Provided for non-commercial research and education use. Not for reproduction, distribution or commercial use.

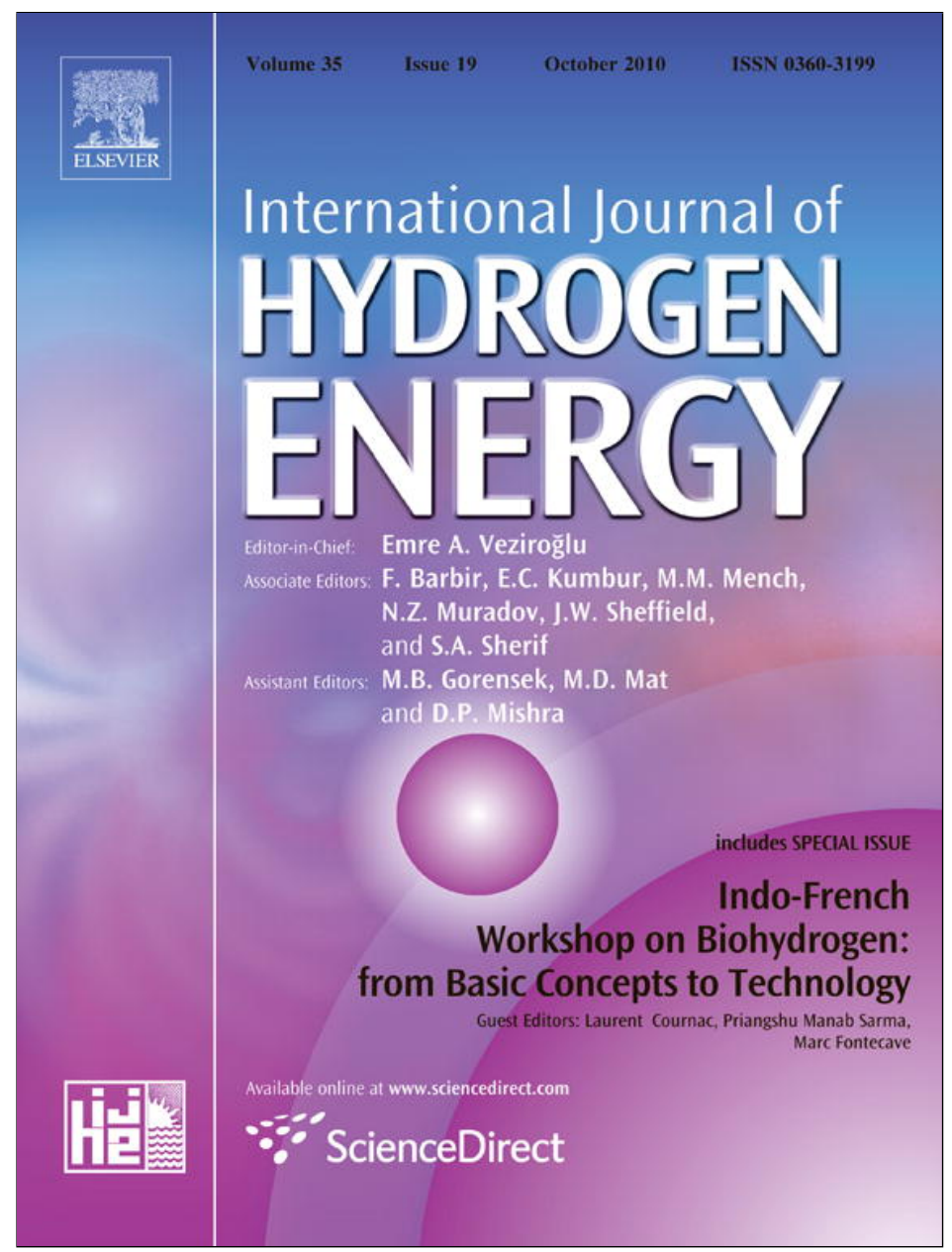

This article appeared in a journal published by Elsevier. The attached copy is furnished to the author for internal non-commercial research and education use, including for instruction at the authors institution and sharing with colleagues.

Other uses, including reproduction and distribution, or selling or licensing copies, or posting to personal, institutional or third party websites are prohibited.

In most cases authors are permitted to post their version of the article (e.g. in Word or Tex form) to their personal website or institutional repository. Authors requiring further information regarding Elsevier's archiving and manuscript policies are encouraged to visit:

http://www.elsevier.com/copyright 


\title{
Co-Magneli phases electrocatalysts for hydrogen/oxygen evolution
}

\author{
Perica Paunovića,*, Orce Popouski ${ }^{b}$, Emilija Fidančeuska ${ }^{a}$, Bogdan Ranguelov ${ }^{c}$, \\ Dafinka Stoeuska Gogouska ${ }^{a}$, Aleksandar T. Dimitrov ${ }^{a}$, Suetomir Hadži Jordanov ${ }^{a}$ \\ a Faculty of Technology and Metallurgy, University "Sts. Cyril and Methodius”, Ruger Bošković Str., 16, 1000 Skopje, The Former Yugolav \\ Republic of Macedonia \\ ${ }^{\mathrm{b}}$ Military Academy, Mihajlo Apostolski Str., b.b., 1000 Skopje, The Former Yugolav Republic of Macedonia \\ ${ }^{\mathrm{c}}$ Institute of Physical Chemistry, Bulgarian Academy of Sciences, Acad.G. Bonchev Str., Bl.11, 1113 Sofia, Bulgaria
}

\section{A R T I C L E I N F O}

\section{Article history:}

Received 27 June 2010

Received in revised form

19 July 2010

Accepted 24 July 2010

Available online 19 August 2010

\section{Keywords:}

Magneli phases

Ebonex

Co

Hydrogen evolution

Oxygen evolution

\begin{abstract}
A B S T R A C T
The subject of this work is the use of non-stoichiometric titanium oxides - Magneli phases as support material of Co-based electrocatalysts aimed for hydrogen/oxygen evolution reaction. Commercial micro-scaled Ebonex (Altraverda, UK) was mechanically treated for $4,8,12,16$ and $20 \mathrm{~h}$ and further Co metallic phase was grafted by sol-gel method. Morphology of Co/Ebonex electrocatalysts was observed by means of TEM and SEM microscopy, while electrochemical behavior by means of cyclic voltammetry and steadystate galvanostatic method.

As the duration of mechanical treatment increases, the size of Magneli phases decreases, and consequently catalytic activity of the corresponding electrocatalysts increases. Structural characteristics of the electrocatalysts deposited on Ebonex treated for 16 and $20 \mathrm{~h}$ are very similar. Also, these electrocatalysts show similar electrocatalytic activity for both hydrogen and oxygen evolution reaction. So, optimal duration of mechanical treatment of Magneli phases is in the range of $16-20 \mathrm{~h}$.

Catalytic activity for hydrogen evolution of the studied electrocatalysts is inferior related to the corresponding catalysts deposited on carbonaceous support materials such as activated multiwalled carbon nanotubes or Vulcan XC-72 $+\mathrm{TiO}_{2}$ (anatase). This inferiority is due to lower real surface area of the Magneli phases.

Catalytic behavior for oxygen evolution achieves its maximal value even at the catalyst deposited on Ebonex treated for $12 \mathrm{~h}$ and it is very promising related to the similar electrocatalytic system such as CoPt/Ebonex.
\end{abstract}

(c) 2010 Professor T. Nejat Veziroglu. Published by Elsevier Ltd. All rights reserved.

\section{Introduction}

Recent intensive development of hydrogen economy as an alternative energy system in the future imposes invention and research on new effective electrode materials. The modern electrode materials are composed of nanostructured catalytic phase dispersed over the support material that has to possess several very important characteristics, such as: i) highly developed surface area to provide better dispersion of the nano-scaled catalytic particles; ii) high electric conductivity to allow efficient electron transfer to ions involved in the electrochemical reactions, iii) mechanical and chemical stability and iv) to improve intrinsic catalytic activity of the active catalytic phase through the strong metal-support interaction (SMSI) [1,2]. Carbon nanostructured materials such as carbon blacks are commercially the most used support material $[3,4]$,

\footnotetext{
* Corresponding author. Tel./fax: +38923064 392.

E-mail address: pericap@tmf.ukim.edu.mk (P. Paunović). 0360-3199/\$ - see front matter ๑ 2010 Professor T. Nejat Veziroglu. Published by Elsevier Ltd. All rights reserved. doi:10.1016/j.ijhydene.2010.07.143
} 
due to their high surface area, conductivity and compositional homogeneity. Recently, implementation of carbon nanotubes as a catalyst support is the subject of intensive research [5-7]. But, carbon shows moderate interaction with the catalytic phase and lack of stability especially in anodic electrode reaction such as oxygen evolution.

To improve interaction with catalytic phase and consequently catalytic activity, d-metal (or its compound) with lower electronic density in the d-band has been involved. This improvement of the catalytic activity is based on the Jakšić's theory for hypo-hyper d-electrocatalysts formation [8,9]. In this context, $\mathrm{TiO}_{2}$ has shown unique SMSI behavior [1,2]. Also, $\mathrm{TiO}_{2}$ as well as other metal oxides have high chemical stability, but they are non-conductive. Thus, their use in water electrolysis or energy conversion in fuel cells must be accompanied by the carbon phase.

Some of the transition metal oxides have potential to be possible electrode or support materials [10]. Recently, socalled Magneli phases, i.e. titanium non-stoichiometric oxides with general formula $\mathrm{Ti}_{n} \mathrm{O}_{2 n-1}(4<n<10)$, have been considered as a very promising support material due to their high chemical stability and high electric conductivity. Especially, the first two suboxides of the series $\left(\mathrm{Ti}_{4} \mathrm{O}_{7}\right.$ and $\left.\mathrm{Ti}_{5} \mathrm{O}_{9}\right)$ show the highest conductivity of $\approx 1500 \mathrm{~S} \mathrm{~cm}^{-1}$ (for single crystal) [11]. Structure, physical properties and electrochemical behavior of the Magneli phases in various media and application are given elsewhere $[12,13]$. They show high overpotential for both hydrogen and oxygen evolution as well as slow charge transfer kinetics. Because of this, they are more suitable as support material than the electrode one $[14,15]$.

As a support material, Magneli phases have bifunctional role - support (high conductivity dispersion) and improvement of intrinsic catalytic activity of the electrocatalyst as a result of the interaction with metallic catalytic phase (SMSI). On the other hand, they show high chemical stability. But, their main disadvantage is the low specific surface area [16]. The only commercial product known as Ebonex ${ }^{\circledR}$ (Altraverda Inc., UK) is micro-scaled material. In the Jakšić's series of investigations [16-18] for oxygen reduction reaction, the maximal achieved specific surface area by mechanical treatment of Ebonex was $1.6 \mathrm{~m}^{2} \mathrm{~g}^{-1}$. Small specific surface area cannot provide sufficient dispersion of the nano-scaled catalytic phase. "Top-down" methods for reduction of Ebonex grain size and further appropriate impregnation method for nano-scaled metallic phase grafting over the Ebonex support (boron-hydride method [19] or ultrasonic blending of Pt salt solution and previously mechanically treated Ebonex [16,17]) can give satisfactory results for oxygen reduction reaction. Synthesized Pt/Ebonex catalyst, in comparison with polycrystalline Pt, has shown the enhancement of the catalytic activity for oxygen reduction reaction [17].

The aim of this work is to determine the maximal possibility of mechanical reduction of Ebonex grains used as electrode support material for water electrolysis. As metallic phase grafted over the Ebonex support, cobalt (non-platinum metal) was used. The synthesized Co/Ebonex catalysts are tested for hydrogen/oxygen evolution. This is continuity of our previous papers [20-24] concerned with the development of non-platinum electrocatalysts for water electrolysis.

\section{Experimental}

First of all, Magneli phases (trade name Ebonex ${ }^{\circledR}$, Altraverda, UK) were mechanically treated by Fritsch Planetary Mill (Pulverisisette 5) without binder. The dry ball milling was performed with acceleration of balls of $200 \mathrm{rpm}$, for different duration $-4,8,12,16$ and $20 \mathrm{~h}$. The ball diameter was $1 \mathrm{~cm}$, while the mass ratio of balls vs. treated material was 3:1.

The size of the Ebonex grains was determined by means of TEM analysis. TEM observation was performed by Transmission Electron Microscope JEOL JEM 100B with $60 \mathrm{kV}$ accelerating voltage.

In the next experimental phase, electrocatalysts were prepared. The studied electrocatalysts contain $10 \mathrm{wt} . \%$ Co metallic phase deposited on the previously mechanically treated Magneli phases. These electrocatalysts are of hypo-hyper d-type, whereat Co is a hyper d-metallic phase, while Magneli phases are hypo d-oxide phase. They were prepared using sol-gel procedure [20]. As precursors for hyper d-metallic phase organometallics were used (Co-2,4-pentanedionate, Alfa Aesar, Johnson Matthey, $\mathrm{GmbH}$ ). Co-2,4-pentanedionate was added into dispersed Magneli phases in anhydrous ethanol. This mixture was evaporated at $60^{\circ} \mathrm{C}$ with continuous intensive stirring until fine powder was obtained. This procedure was repeated for each different mechanically treated sample of Magneli phases. Shown in Table 1 is the scheme of the studied electrocatalysts samples.

The prepared electrocatalysts series were observed by SEM microscopy, while the surface composition was determined by means of EDS analysis. For this purpose, Scanning Electron Microscope JEOL 6390 with EDS Oxford Inca Energy 350 was used.

The electrochemical characterization was performed by means of cyclic voltammetry and steady-state galvanostatic method. Working electrodes (three-phase gas-diffusion electrodes) were prepared by hot pressing at $300{ }^{\circ} \mathrm{C}$ and pressure of $300 \mathrm{~kg} \mathrm{~cm}^{-2}$ [25]. They consist of two layers: i) catalytic layer facing the electrolyte, covered by tested electrocatalyst with low amount of polytetrafluoroethylene (PTFE) and ii) gas-diffusion layer facing the gas side consisted of Vulcan XC-72 bonded with PTFE. Electrochemical investigations were performed using AMEL equipment (Function Generator AMEL 568, Potentiostat/ Galvanostate AMEL 2053 and software package SOFTASSIST 2.0). The counter electrode was of platinum wire and the reference electrode $-\mathrm{Hg} / \mathrm{HgO}$. The electrolyte was an aqueous solution of 3.5 M KOH (p.a., Merck) at room temperature.

Table 1 - Duration of the mechanical treatment on the support material of electrocatalysts with the general composition of $10 \%$ Co $+90 \%$ Ebonex.

Duration of the mechanical treatment of Ebonex, $h$

\begin{tabular}{rr}
\hline Sample 1 & 0 \\
Sample 2 & 4 \\
Sample 3 & 8 \\
Sample 4 & 12 \\
Sample 5 & 16 \\
Sample 6 & 20
\end{tabular}




\section{Results and discussions}

\subsection{Effect of the mechanical activation on the size of support material}

To determine the size of the support material particles, TEM analysis was performed (Fig. 1). The support's grains shown in corresponding TEM images were chosen as the average ones after comprehensive scan of the sample surface. The size of the support particles decreases from $700 \mathrm{~nm}$ in the sample with untreated Magneli phases to $215 \mathrm{~nm}$ in the sample with Magneli phases treated for $20 \mathrm{~h}$. The influence of the mechanical treatment duration on the average size of the particles of Magneli phases, determined by TEM analysis, is shown in Fig. 2. The catalysts containing support material treated for 16 and $20 \mathrm{~h}$ show very close values of support's particle size, 230 and $215 \mathrm{~nm}$ respectively.

Shown in Fig. 3 are SEM images of the electrocatalysts containing cobalt deposited on Magneli phases mechanically treated for different time. The catalysts support (Magneli phases) forms mostly micro-scaled and less submicron aggregates, while Co phase - the active catalytic centers are very small and uniformly dispersed over the support's aggregates. In our previous studies [7,21-24] was shown (by XRD and TEM analysis) that the size of Co particles, produced by the mentioned sol-gel method and corresponding organometallic precursor, is near $2 \mathrm{~nm}$. Thus, one can consider that Co particles in all studied samples are of the same size, near $2 \mathrm{~nm}$. The presence of holes between the aggregates is evident, which contributes to better inter-particle porosity and higher specific surface area. This is favorable for electrocatalytic activity. It is
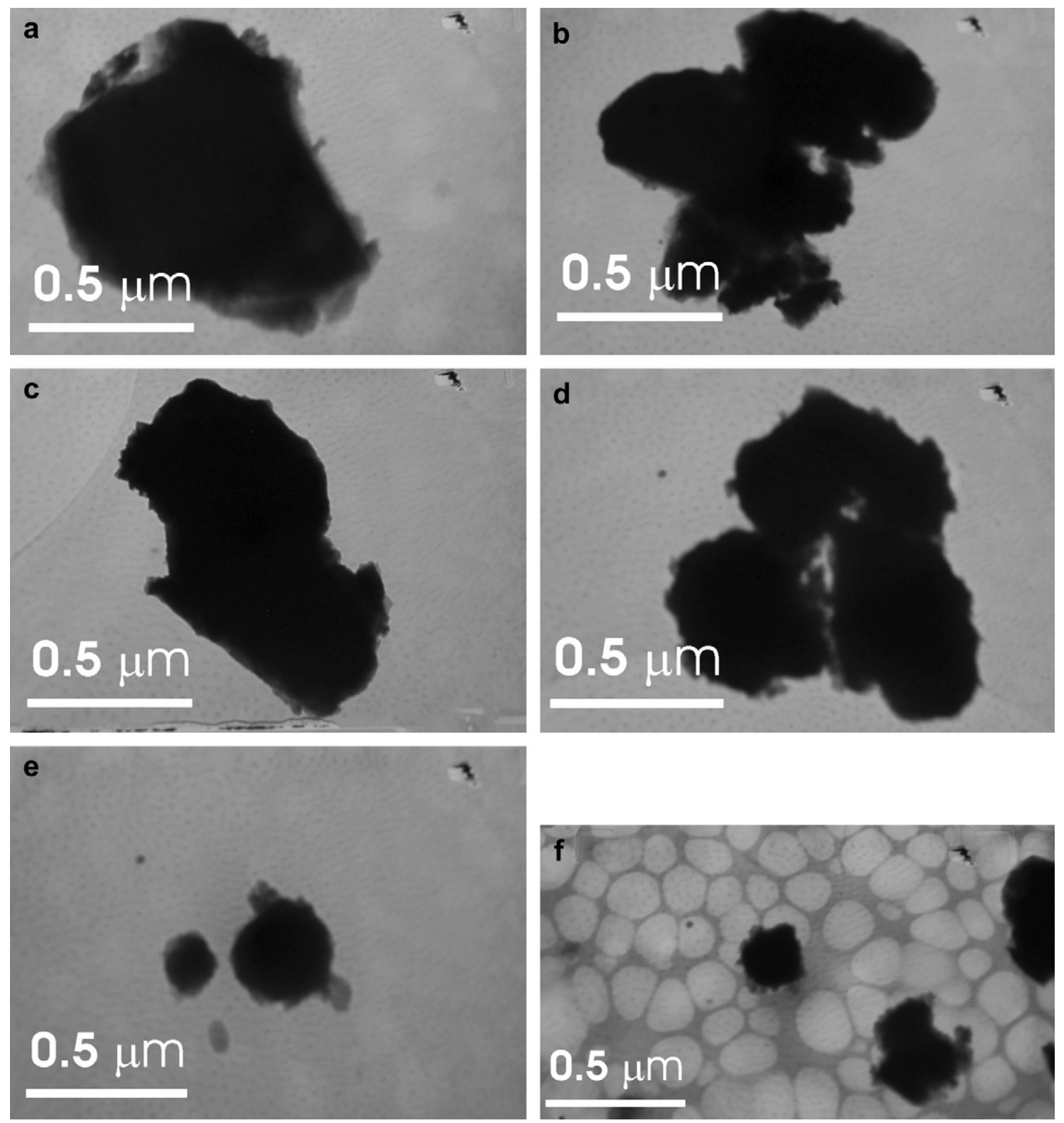

Fig. 1 - TEM images of the studied electrocatalysts deposited on Magneli phases mechanically treated for: a) $0 \mathrm{~h}, \mathrm{~b}) \mathbf{4 h}$, c) $8 \mathrm{~h}, \mathrm{~d}) 12 \mathrm{~h}$, e) $16 \mathrm{~h}$ and f) $20 \mathrm{~h}$. 


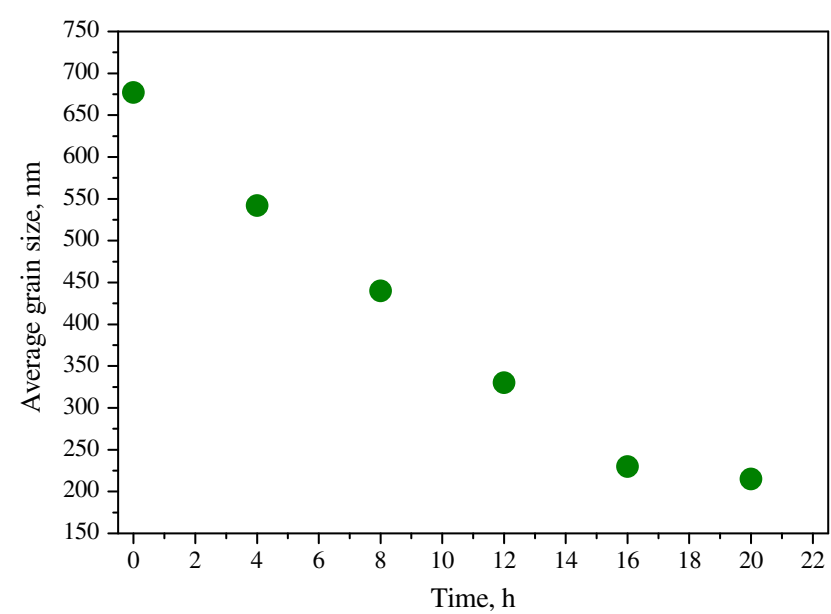

Fig. 2 - Plot of dependence between duration of mechanical treatment and average particle size of Magneli phases determined by TEM analysis.

well visible from Fig. 3a, that the electrocatalyst deposited on non-treated Magneli phases shows very large aggregates and lack of holes. As the time of mechanical treatment of Magneli phases increases, the aggregate size decreases, the number of holes between aggregates increase and consequently interparticle porosity increases. As in the previous TEM analysis, the last two catalysts deposited on support mechanically treated for 16 and $20 \mathrm{~h}$ (Fig. 3e and f), show similar SEM characteristics, superior related to the other samples.

According to EDS analysis (see Table 2) performed on the corresponding points within the SEM images, it is perceptible that surface concentration of cobalt phase varies in the studied samples. As the duration of mechanical treatment rises, the Co surface concentration decreases. But, the electrocatalysts deposited on support treated for 16 and $20 \mathrm{~h}$ show almost the same surface quantity of Co. These two catalysts show very close average size of both the catalyst's aggregates (SEM analysis, Fig. 3) and support's particles (TEM analysis, Figs. 1 and 2). Thus, the surface concentration of metallic catalytic phase (cobalt) depends on the size of catalyst support. Weight percentage of $\mathrm{Ti}, \mathrm{Co}$ and $\mathrm{O}$ point out that Co on the surface is in oxide state. Also, one can say that Magneli phases were not contaminated by the balls of the planetary mill during the mechanical treatment.

\subsection{Cyclic voltammetry}

The voltammogram of Co/Ebonex catalyst (Fig. 4) is typical for Co in alkaline electrolyte [26]. This shape is characteristic for all studied electrocatalysts, differing only in the values of the current density, i.e. in the intensities of corresponding peaks of surface or electrode processes. The peak A at $-0.55 \mathrm{~V}$ vs. $\mathrm{Hg} /$ $\mathrm{HgO}$ reference electrode, corresponds to transformation of $\mathrm{Co}$ (0) to $\mathrm{Co}(\mathrm{II})$. Its asymmetric shape is result of heterogeneous forming of $\mathrm{Co}(\mathrm{OH})_{2}$ and $\mathrm{CoO}$ into so called sandwich-structure $\mathrm{Co} / \mathrm{CoO} / \mathrm{Co}(\mathrm{OH})_{2}$ [27]. The transformation of $\mathrm{Co}$ (II) to $\mathrm{Co}$ (III) is shown by peak $\mathrm{B}$. There is also a sandwich-structure $\mathrm{CoO} / \mathrm{Co}$ $(\mathrm{OH})_{2} / \mathrm{Co}_{3} \mathrm{O}_{4}$ [28], which implies asymmetry of the peak. The peak $\mathrm{B}^{\prime}$ near $-0.26 \mathrm{~V}$, denotes the opposite transformation. It is obvious that the reaction $\mathrm{Co}$ (II) $\leftrightarrows \mathrm{Co}$ (III) is irreversible. The peak $C$ denotes oxygen evolution reaction. The stretched peak $\mathrm{A}^{\prime}$ in the potential region of -0.7 to $-1 \mathrm{~V}$ denotes mainly $\mathrm{Co}$ (II) to $\mathrm{Co}(0)$ reduction. The shifted potential related to the peak A indicates irreversibility of this transformation too. The peak $D$ corresponds to occurrence of hydrogen evolution reaction.

One could regard the gas-diffusion electrode as a complex, composed of number of individual nano-scaled electrodes. The electrical contact between separate grains is not always with zero resistance, so that the existence of IR drop is possible component for some grains. Consequently, the real electrochemical potential of individual grains varies over a span of values. This causes the peak potential, as well as the whole position of the peak, to vary, thus causing the overall peak to appear less shaped and irregular.

Shown in Fig. 5 is the voltammogram of pure Magneli phases mechanically treated for $20 \mathrm{~h}$. There are more, but less structured peaks (A, B, C, $\mathrm{A}^{\prime}, \mathrm{B}^{\prime}$ and $\mathrm{C}^{\prime}$ ) of surface processes with intensities considerably lower than those originating from the corresponding Co-based catalyst. These peaks indicate transition of the non-stoichiometric titanium oxides from lower to higher oxidation state (peaks A, B and C) and the opposite transition to lower oxidation state consequently (peaks $\mathrm{A}^{\prime}, \mathrm{B}^{\prime}$ and $\mathrm{C}^{\prime}$ ). Because Magneli phases are composed of many different non-stoichiometric titanium oxides in homologous order defined by $\mathrm{Ti}_{n} \mathrm{O}_{2 n-1}(4<n<10)$, it is very difficult to define the exact surface reaction or to clarify distinction between the different surface reactions that occur. So, each peak of the surface reactions is a resultant of the oxidation state transitions of all non-stoichiometric oxides present in the Magneli phases. These peaks cannot be registered in the previous voltammogram of the Co-based electrocatalysts (Fig. 4) because their intensity is approximately 10-20 times lower than that of the peaks originating from Co surface reactions.

\subsection{Catalytic activity for hydrogen and oxygen evolution}

Electrocatalytic activity of the studied Co/Ebonex electrocatalysts for hydrogen evolution is shown in Fig. 6. It is well noticeable that while the duration of mechanical treatment of Magneli phases rises, i.e. the size of the catalyst support particles decreases, the catalytic activity for hydrogen evolution increases. This rising trend of catalytic activity is more evident in the diagram shown in Fig. 7. It shows dependence between the overpotential for hydrogen evolution at $100 \mathrm{~mA} \mathrm{~cm}^{-2}$ and the time of the mechanical treatment. From both figures, it is clear that the catalytic activities of Co electrocatalysts deposited on Magneli phases treated for 16 and $20 \mathrm{~h}$ are very close. This is predictable from the above exposed SEM, EDS and TEM analysis. In all analysis, the structural characteristics of both electrocatalysts such as size of the catalyst's aggregates and particles and distribution of Co catalytic centers over the catalyst's surface were very similar (see Section 3.1). This means that the optimal duration of the mechanical treatment of Magneli phases is in the range of 16-20 h. Further mechanical treatment cannot decrease the particle size of Magneli phases and consequently cannot 

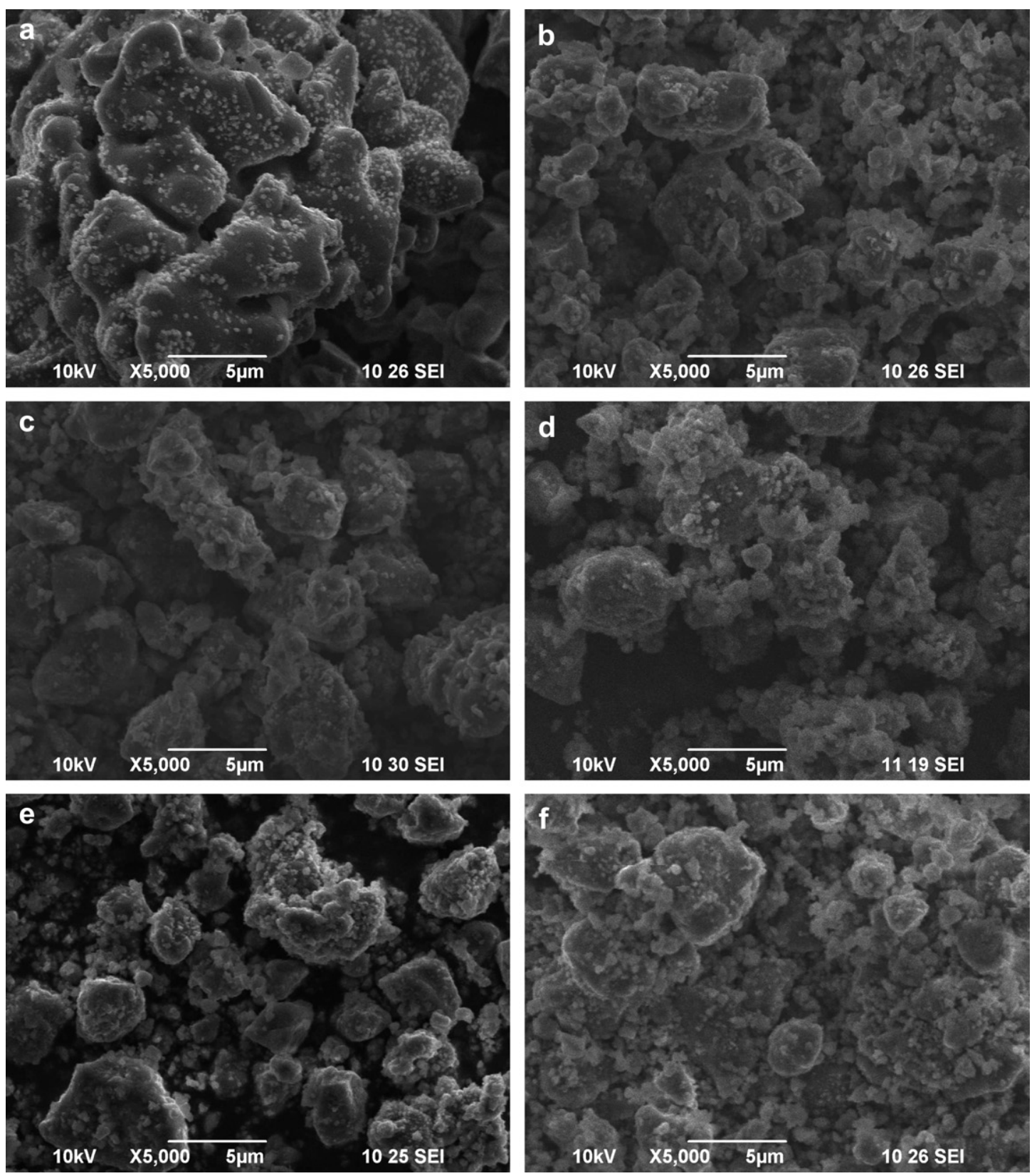

Fig. 3 - SEM images of the studied Co-based electrocatalysts deposited on Magneli phases mechanically treated for: a) $0 \mathrm{~h}$, b) $4 \mathrm{~h}, \mathrm{c)} 8 \mathrm{~h}, \mathrm{~d}) 12 \mathrm{~h}$, e) $16 \mathrm{~h}$ and f) $20 \mathrm{~h}$.

increase the catalytic activity of Co/Ebonex for hydrogen evolution. This can be explained by the fact that during mechanical reduction of the particle size, the increase of the surface area is followed by considerably increase of the

Table 2 - Composition of the electrocatalysts determined by EDS analysis.

\begin{tabular}{lcclcr} 
& O & Ti & Co & $\mathrm{TiO}_{2}$ & $\mathrm{CoO}$ \\
\hline Sample 1 & 38.99 & 52.72 & 8.3 & 89.45 & 10.55 \\
Sample 4 & 49.28 & 44.06 & 6.65 & 91.55 & 8.45 \\
Sample 5 & 38.74 & 55.74 & 5.52 & 92.98 & 7.02 \\
Sample 6 & 38.74 & 55.76 & 5.50 & 93.01 & 6.99 \\
\hline
\end{tabular}

surface energy making the treated material thermodynamically unstable. The mechanism by which the material can be transferred to thermodynamically stable state (reduction of the overall energy) is agglomeration of the grains.

Let's compare catalytic activity of the best behaved catalyst in this series (Co/Ebonex treated for $20 \mathrm{~h}$ ) with corresponding electrocatalysts deposited on different support materials from the previous studies (see Table 3). As an indicator for electrocatalytic activity for hydrogen evolution, overpotential at reference current density of $60 \mathrm{~mA} \mathrm{~cm}^{-2}$ is taken.

Comparing Co/Ebonex catalyst (No. 1 in Table 3) with corresponding Co catalyst deposited on Vulcan XC-72 (No. 2 in Table 3 [23]), one can see slightly better catalytic activity of the Co/Ebonex expressed by $15 \mathrm{mV}$ lower overpotential for 


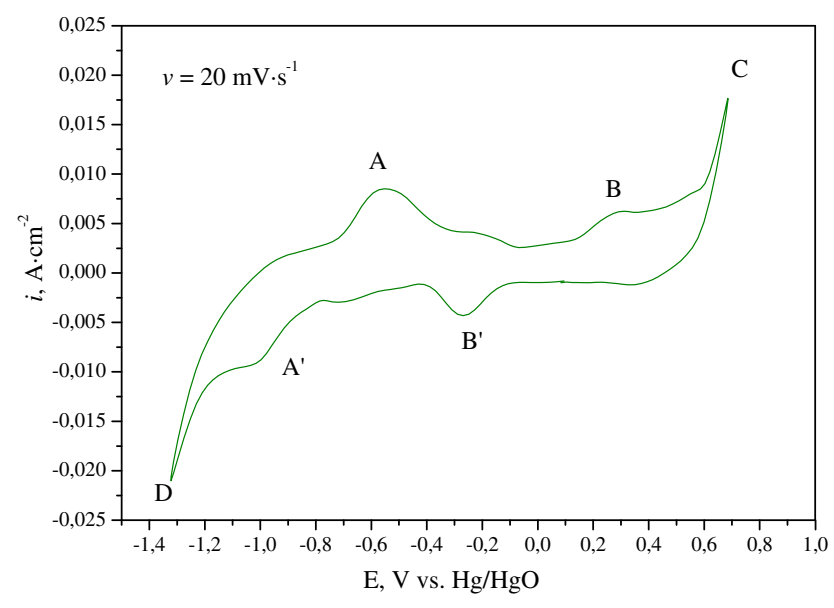

Fig. 4 - Cyclic voltammogram of the Co electrocatalyst deposited on Magneli phases mechanically treated for $20 \mathrm{~h}$.

hydrogen evolution. Because Co phase in both cases has the same structural characteristics, the difference in the catalytic activity is a result of different properties of the catalyst's support. Vulcan XC-72 has very high surface area $\left(\approx 250 \mathrm{~m}^{2} \mathrm{~g}^{-1}\right)$, considerably higher than studied Magneli phases, thus it is expected the catalyst deposited on Vulcan XC-72 to show better activity. But, due to the nature of Magneli phases - titanium oxides, they behave as hypo d-component which interacts to metallic hyper d-phase (Strong Metal-Support Interaction, SMSI) achieving synergetic effect of intrinsic catalytic activity for hydrogen evolution. Thus, the contribution of lower real surface area of the Co/Ebonex catalyst in the whole catalytic activity is compensated with considerably improved intrinsic catalytic activity, resulting in better activity for hydrogen evolution related to corresponding Co catalyst deposited on Vulcan XC-72.

Co electrocatalyst deposited on grafted $\mathrm{TiO}_{2}$ (anatase) on the Vulcan XC-72 (No3 in Table 3 [23]) shows higher catalytic activity for hydrogen evolution than that of Co/Ebonex, expressed by difference in overpotential for $85 \mathrm{mV}$. This rise of catalytic activity is result of both synergetic increase of intrinsic activity through hypo-hyper d-interaction between

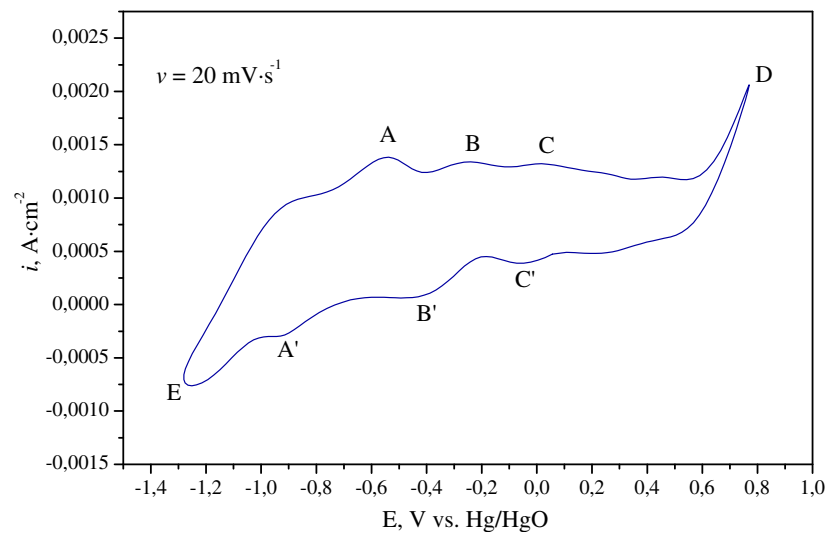

Fig. 5 - Cyclic voltammogram of the pure Magneli phases mechanically treated for $20 \mathrm{~h}$.

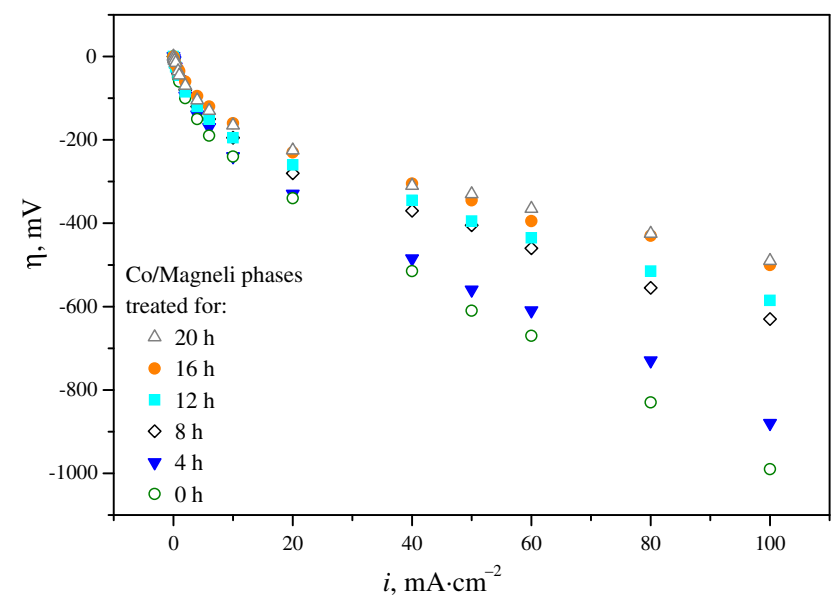

Fig. 6 - Polarization curves of the studied electrocatalysts for hydrogen evolution reaction.

Co and anatase and the highly developed surface area of Vulcan XC-72.

Further replacement of Vulcan XC-72 with activated multiwalled carbon nanotubes (No. 4 in Table 3 [24]) contributes to supplementary rise of the catalytic activity and the overpotential difference with the studied Co/Ebonex electrocatalyst shifted to even $150 \mathrm{mV}$. This rise of the catalytic activity is a result of very high real surface area of activated MWCNTs (twice higher than that of Vulcan XC-72 [23,29]) as well as improved trans-particle porosity. Due to the intrinsic geometric shape of MWCNTs (empty cylinders ordered one over the other), they possess inner holes, so the inner (transparticle) porosity of MWCNTs is considerably higher.

The inferior catalytic behavior of the studied Co/Ebonex electrocatalyst is result of poorer surface characteristics of Magneli phases related to the Vulcan XC-72 and MWCNTs. The lower surface area is a result of relatively large grains of Magneli phases (>200 nm). This study points out that this size of grains and further catalytic activity of Co/Ebonex

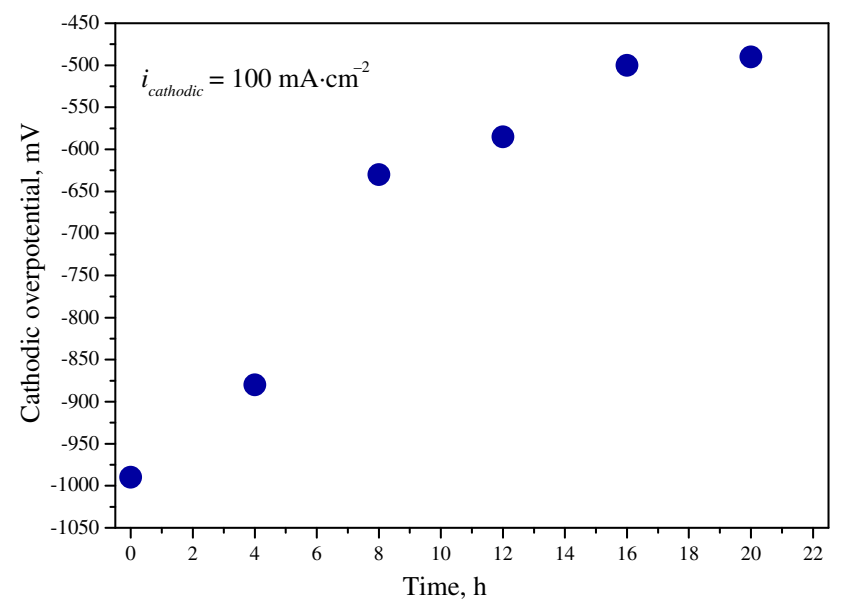

Fig. 7 - Plot of dependence between duration of mechanical treatment of the Magneli phases and overpotential for hydrogen evolution reaction at current density of $100 \mathrm{~mA} \mathrm{~cm}^{-2}$. 
Table 3 - Comparison of the catalytic activity of the Co/ Ebonex electrocatalysts with corresponding Co-based electrocatalysts deposited on different catalyst supports.

\begin{tabular}{llcl} 
No & \multicolumn{1}{c}{ Electrocatalyst } & $\eta_{60} / \mathrm{mV}$ & Ref. \\
\hline 1 & Co/Ebonex (Ebonex treated for $20 \mathrm{~h})$ & -365 & - \\
2 & $\mathrm{Co} /$ Vulcan XC-72 & -380 & {$[23]$} \\
3 & $\mathrm{Co} / \mathrm{TiO}_{2} /$ Vulcan XC-72 & -280 & {$[23]$} \\
4 & $\mathrm{Co}_{\mathrm{TiO}_{2} / \mathrm{MWCNTs}}$ & -215 & {$[24]$} \\
5 & $\mathrm{CoPt}_{\mathrm{TiO}} / \mathrm{MWCNTs}$ & -115 & {$[24]$} \\
\hline
\end{tabular}

electrocatalyst is maximum achievement of the mechanical reduction of micro-scaled commercial Ebonex.

The electrocatalytic activity for oxygen evolution reaction is shown on the diagram in Fig. 8. Normally, as the time of the mechanical reduction of Ebonex grains rises, the catalytic activity of corresponding Co/Ebonex catalysts for oxygen evolution increases. This is expressed by decrease of overpotential at current density of $100 \mathrm{~mA} \mathrm{~cm}^{-2}$ from $600 \mathrm{mV}$, for catalyst deposited on untreated Ebonex, to $360 \mathrm{mV}$ for corresponding catalyst deposited on Ebonex treated for $20 \mathrm{~h}$ (see Fig. 9). But in this case, the catalytic activity reaches its maximal value even at catalyst deposited on Ebonex treated for $12 \mathrm{~h}$. The difference between the last three electrocatalyst (Ebonex treated for 12, 16 and $20 \mathrm{~h}$ ) is very small, thus the further mechanical activation of Magneli phase would not give further improvement of catalytic activity for oxygen evolution as well. Also, catalytic activity of the last three electrocatalyst $\left(270-290 \mathrm{mV}\right.$ at $\left.60 \mathrm{~mA} \mathrm{~cm}{ }^{-2}\right)$ is very satisfactory, compared to other similar electrocatalysts for oxygen evolution, for example, PtCo/Ebonex catalyst produced by boron-hydride reduction [19].

The good catalytic behavior for oxygen evolution is connected to the formation of surface oxides and interaction between metallic phase (Co) and catalyst support (Magneli phases). Metal-support interaction was clarified above. The electrode surface is composed of the oxide support and Co which is in oxide state at potentials close to oxygen evolution region (see. Fig. 4). In this case, Magneli phases behave not only as support material, but also, as an active oxide electrode.

The surface structure of the electrode in the solution is the feature that distinguishes the oxide electrodes [30]. Their

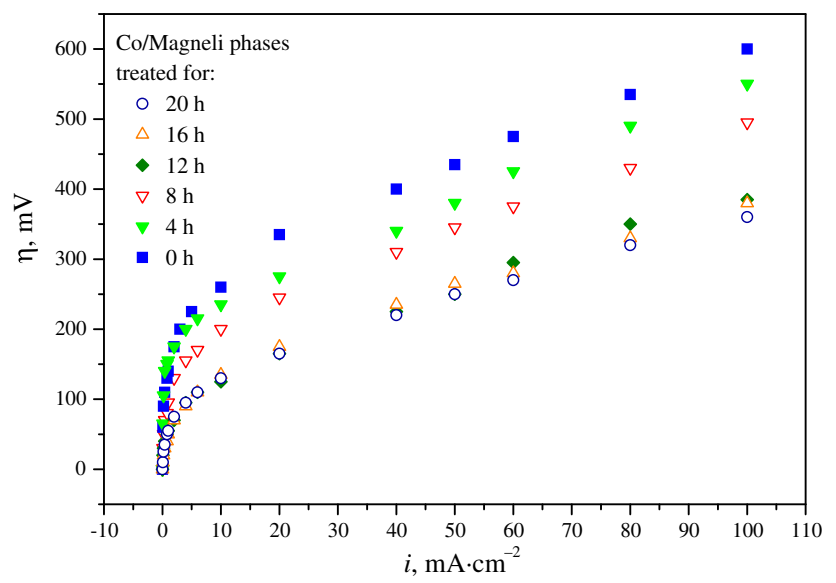

Fig. 8 - Polarization curves of the studied electrocatalysts for oxygen evolution reaction.

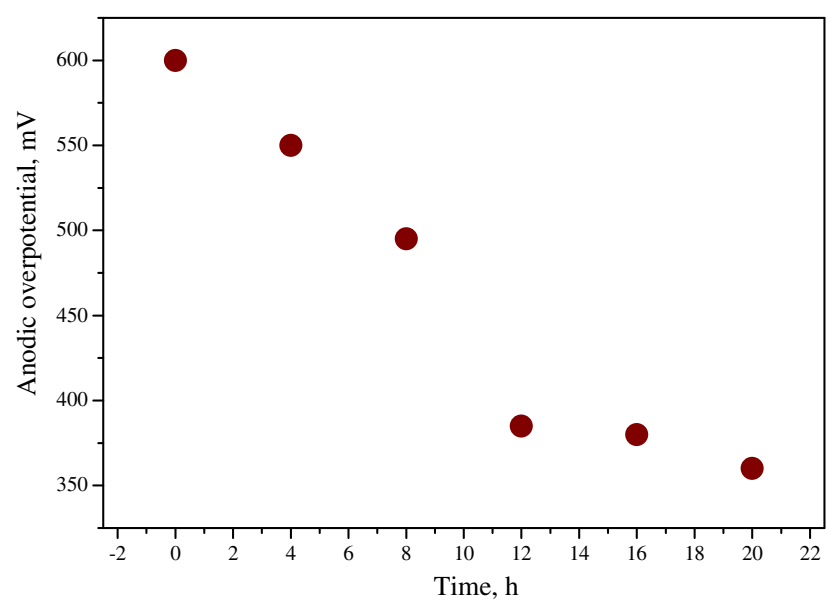

Fig. 9 - Plot of dependence between duration of mechanical treatment of the Magneli phases and overpotential for oxygen evolution reaction at current density of $100 \mathrm{~mA} \mathrm{~cm}^{-2}$.

surface is with high energy content and with strong hydrophilic character, so that it attracts water molecules and gives a layer of $\mathrm{OH}^{-}$groups on top of the oxide. This layer mediates the action of the oxide's surface with the solution species. The $\mathrm{OH}^{-}$groups are responsible for the exhibited electrocatalytic activity. The mechanism of surface charging of oxidized catalysts is quite different from that of bare metal surfaces, since it is governed by the $\mathrm{pH}$-dependent acid-base dissociation of the surface $\mathrm{OH}^{-}$groups. Behaving as weak acids or basis, these groups exchange protons with the solution. This is the basis of the mechanism by which the inner sites can be active in reactions involving water molecules [31].

\section{Conclusion}

The investigations presented in this paper were motivated by the idea to use Magneli phase as catalyst support for electrocatalysts aimed for hydrogen/oxygen evolution, instead of carbonaceous support materials. According to the achieved results the follow conclusions can be drawn:

1. As a result of the mechanical treatment, the size of the Magneli phases decreases as duration of the treatment increases, from $700 \mathrm{~nm}$ for untreated Ebonex to near $200 \mathrm{~nm}$ for electrocatalysts treated for 16 and $20 \mathrm{~h}$.

2. The changes of the structural characteristics observed by TEM, SEM and EDS analysis as well as of the catalytic activity point out that the last two electrocatalysts deposited on Magneli phases treated for 16 and $20 \mathrm{~h}$ show very similar structural and electrochemical characteristics. So, the optimal duration of mechanical treatment of Magneli phases is in the range of $16-20 \mathrm{~h}$.

3. Catalytic activity for hydrogen evolution increases as the duration of the mechanical treatment of catalyst support increases, i.e. particle size of catalyst support decreases. The highest catalytic activity show electrocatalysts deposited on Magneli phase treated for 16 and $20 \mathrm{~h}$. But, this 
activity is inferior related to the corresponding electrocatalysts deposited on other support materials such as Vulcan XC-72 $+\mathrm{TiO}_{2}$ (anatase) or multiwalled carbon nanotubes, due to lower surface area of Magneli phases.

4. Also, the catalytic activity for oxygen evolution increases as the duration of the mechanical treatment of catalyst's support increases. In this case, high activities were achieved even at shorter duration of the mechanical treatment of support material $-12 \mathrm{~h}$. Catalytic activity for oxygen evolution shows superior values related to the similar catalytic systems based on CoPt/Ebonex. During oxygen evolution, Magneli phases are not only support material, but also, active catalytic phase for oxygen evolution.

The above results point out the need to apply "Bottom-Up" approach to synthesize nano-scaled non-stoichiometric titanium oxides (below $100 \mathrm{~nm}$ ) instead of here applied "Top-Down" approach, whereat Magneli phases were produced in submicronscale. This will considerably improve the catalytic activity of nonplatinum electrocatalysts for hydrogen evolution, while extra-ordinary catalytic activity for oxygen evolution is expected.

\section{R E F E R E N C E S}

[1] Tauster SJ, Fung SC, Garten RL. Strong metal-support interactions. Group 8 noble metals supported on titanium dioxide. J Am Chem Soc 1978;100:170-5.

[2] Neophytides SG, Zaferiatos S, Papakonstantnou GD, Jakšić JM, Paloukis FE, Jakšić MM. Extended brewer hypo-hyper-d-interionic bonding theory-I. Theoretical considerations and examples for its experimental confirmation. Int J Hydrogen Energy 2005;30:131-47.

[3] Kinoshita K. Carbon, electrochemical and physicochemical properties. New York: John Wiley\& Sons; 1988.

[4] Budevski E. Structural aspects of fuel cell electrodes. J Optoelec Adv Mater 2003;5:1319-25.

[5] Lee K, Zhang J, Wang H, Wilinson DP. Progress in the synthesis of carbon nanotube- and nanofiber-supported Pt electrocatalysts for PEM fuel cell catalysis. J Appl Electrochem 2006;36:507-22.

[6] Serp P, Corrias M, Kalck P. Carbon nanotubes and nanofibers in catalysis. Appl Catal A Gen 2003;253:337-58.

[7] Paunović P, Dimitrov AT, Popovski O, Slavcheva E, Grozdanov A, Lefterova E, et al. Effect of activation/purification of multiwalled carbon nanotubes (MWCNTs) on the activity of non-platinum based hypo-hyper d-electrocatalysts for hydrogen evolution. Mat Res Bull 2009;44:1816-21.

[8] Jakšić MM. Advances in electrocatalysis for hydrogen evolution in the light of the Brewer-Engel valence-bond theory. Int J Hydr Energy 1987;12:727-52.

[9] Jakšić MM. Volcano plots along the periodic table, their causes and consequences on electrocatalysis for hydrogen electrode reaction. J New Mater Electrochem Syst 2000;3:153-68.

[10] Trasatti S. Transition metal oxides, versatile materials for electrocatalysis. In: Lipkowski J, Ross PN, editors. New York: VCH Publishers; 1994.

[11] Houlihan JF, Mulay LN. Characterization of and electronic structural studies on the oxides of titanium: E.P.R. linewidths. Mat Res Bull 1971;6:737-42.
[12] Smith JR, Walsh FC, Clarke RL. Electrodes based on Magnéli phase titanium oxides: the properties and applications of Ebonex materials. J Appl Electrochem 1998;28:1021-33.

[13] Scott K, Cheng H. The anodic behaviour of Ebonex in oxalic acid solutions. J Appl Electrochem 2002;32:583-9.

[14] Clarke RL, Pardoe R. Application of ebonex conductive ceramic electrodes in effluent treatment in electrochemistry for a cleaner environment. In: Genders JD, Weinberg NL, editors. New York: The Electrosynthesis Company; 1993.

[15] Kolbrecka K, Przylski. Sub-stoichiometric titanium oxides as ceramic electrodes for oxygen evolution-structural aspects of the voltammetric behaviour of $\mathrm{Ti}_{n} \mathrm{O}_{2 n-1}$. Electrochim Acta 1994;39:1591-5.

[16] LjM Vračar, SLj Gojković, Elezović NR, Radmilović VR, Jakšić MM, Krstajić NV. Magneli phase titanium oxides as catalyst support - electrochemical behavior of Ebonex/Pt catalysts. J New Mater Electrochem Syst 2006;9:99-106.

[17] LjM Vračar, Krstajić NV, Radmilović VR, Jakšić MM. Electrocatalysis by nanoparticles - oxygen reduction on Ebonex/Pt electrode. J Electroanal Chem 2006;587:99-107.

[18] Krstajić NV, LjM Vračar, Radmilović VR, Neophytides SG, Labou M, Jakšić JM, et al. Advances in interactive supported electrocatalysts for hydrogen and oxygen electrode reactions. Surf Sci 2007;601:1949-66.

[19] Slavcheva E, Nikolova V, Petkova T, Lefterova E, Dragieva I, Vitanov T, et al. Electrocatalytic activity of Pt and PtCo deposited on Ebonex by BH reduction. Electrochim Acta 2005;50:5444-8.

[20] Paunović P, Popovski O, Radev I. Investigation of cell assemblies prepared out of electrocatalysts aimed for hydrogen evolution. Bull Chem Technol Macedonia 2005;24: 133-41.

[21] Paunović P, Popovski O, Hadži Jordanov S, Dimitrov A, Slavkov D. Modifications for the improvement of catalyst materials for hydrogen evolution. J Serb Chem Soc 2006;71: 149-65.

[22] Paunović P, Popovski O, Dimitrov AT, Slavkov D, Lefterova E, Hadži Jordanov S. Improvement of performances of complex non-platinum electrode materials for hydrogen evolution. Electrochim Acta 2006;52:1810-7.

[23] Paunović P, Popovski O, Dimitrov AT, Slavkov D, Lefterova E, Hadži Jordanov S. Study of structural and electrochemical characteristics of Co-based hypo-hyper d-electrocatalysts for hydrogen evolution. Electrochim Acta 2007;52:4640-8.

[24] Paunović P, Radev I, Dimitrov AT, Popovski O, Lefterova E, Slavcheva $E$, et al. New nano-structured and interactive supported composite electrocatalysts for hydrogen evolution with partially replaced platinum loading. Int J Hydrogen Energy 2009;34:2866-73.

[25] BG patent appl. no 38581, 1978.

[26] Behl WK, Toni JE. Anodic oxidation of cobalt in potassium hydroxide electrolytes. J Electroanal Chem 1971;31:63-75.

[27] Sato N, Ohtsuka T. Anodic oxidation of cobalt in neutral and basic solution. J Electrochem Soc 1978;125:1735-40.

[28] Burke LD, Murphy OJ. Electrochromic behaviour of oxide films grown on cobalt and manganese in base. J Electroanal Chem 1980;109:373-7.

[29] Paunović P, Dimitrov AT, Popovski O, Slavkov D, Hadži Jordanov S. Effect of carbon nanotubes support in improving the performance of mixed electrocatalysts for hydrogen evolution. Maced J Chem Chem Eng 2007;26:87-93.

[30] Hadži Jordanov S. Towards the year 2000: some aspects of the electrochemistry in the last decades of twentieth century. Bull Chem Technol Macedonia 1997;16:75-88.

[31] Boodts JCF, Trsatti S. Hydrogen evolution on iridium oxide cathodes. J Appl Electrochem 1989;19:255-62. 